\title{
Split-brain Rat: Transfer and Interference of Kindled Amygdala Convulsions
}

\author{
DAN C. MCINTYRE
}

SUMMARY: Rats were subjected to varying degrees of commissurotomy, followed by implantation of a bipolar electrode into each amygdala. After the kindling of six convulsions at one electrode (primary site), the procedure was applied to the contralateral amygdala (secondary site). Convulsions were observed to develop more rapidly, independent of the degree or kind of transection. After 6 secondary site convulsions, the primary site was re-tested and convalsion-triggering was blocked, except in animals with transection of the rostral portion of the corpus callosum (CC).

RESUMÉ: Une commissurotomie de degré variable, suivie d'une implantation bi-amygdalienne d'une électrode bipolaire fut pratiquée chez des rats. Après "kindling" de six convulsions à une électrode (site primaire), la procédure fut répétée à l'amygdale contralatérale (site secondaire). Dans ces conditions les convulsions apparaissent plus vite, peu importe le degré de transection. Après 6 convalsions au site secondaire, on reteste le site primaire oì l'on constate un bloc du déclanchement des convulsions, sauf chez les animaux avec transection de la partie rostrale du corps calleux (CC).
Collectively, the data indicate: (i) amygdala kindling develops a lasting trace which operates through the midbrain or brainstem; (ii) kindling from a second site utilizes this trace; (iii) a series of 6 convalsions produces negative after-effect which manifests itself at the convulsion level via the anterior $C C$; (iv) the anterior $C C$ is important in determining the laterality of the forelimb clonus; and (v) the inter-amygdala propagation of after-discharge is blocked by the combined sectioning of the anterior $C C$ and the anterior commissure.

Ces données indiquent: (i) que le "kindling" amygdalien développe une trace de longue durée qui agit à travers le mésencéphale ou le tronc c'érébral; (ii) que le "kindling" d'un site secondaire utilise cette même trace; (iii) qu'une série de 6 convulsions produit une post-réaction négative qui se manifeste au niveau convulsif via le CC antérieur; (iv) que le CC antérieur est important pour déterminer la latéralité da clonas d'un membre antérieur et enfin (v) que la propagation inter-amygdalienne est bloquée par la combinaison d'une section de la partie antérieure du CC et de la commissure antérieure.
From the Department of Psychology, Carleton University, Ottawa, Canada.

Reprint requests to Dr. D. C. McIntyre, Department of Psychology, Carleton University, Ottawa, Canada.

This research was supported by a NRC Grant to the author.
It has been demonstrated that repeated electrical stimulation of several discrete forebrain structures, particularly in the limbic system, results in the progressive development of electrographic after-discharge (AD) and behavioral automatisms. Eventually the stimulation comes to evoke full motor convulsions. The changes resulting from this stimulation have been termed collectively the "kindling effect" (Goddard, McIntyre, and Leech, 1969). Many, but not all, of the changes involved in kindling have been shown to be reasonably permanent, even in the face of many months of disuse (Goddard et al., 1969; Wada, Sato and Corcoran, 1974).

After a kindled site has been established, behavioral convulsions are acquired more readily by activation of other related sites, particularly the contralateral homotopic structure (Burnham, 1971; Goddard et al., 1969; McIntyre and Goddard, 1973; Racine, 1972; Tanaka, 1972). This transfer has been obtained even after ablation of the original primary site of kindling (McIntyre and Goddard, 1973; Racine, 1972). When a series of convulsions is triggered from this second site, an unexpected suppression of the primary site is observed (Goddard et al., 1969; McIntyre and Goddard, 1973). This interference is most apparent in the total suppression of motor convulsions evoked from that primary site, and requires several repetitions of daily stimulation before a convulsion is again evoked from that primary focus. The interference effect, like the transfer, is not dependent upon the integrity of the site from which it was produced; however, unlike the transfer effect, it is labile over time and decays if the secondary site is 
not activated (McIntyre and Goddard, 1973).

The interhemispheric avenues for achieving the transfer and interference effects have not been delineated. It was the purpose of the present report to determine the commissural intermedians associated with the transfer and interference effects, as manifested between the amygdalae. In addition, assessment was made of the commissures involved in lateralization of AD propagated from the amygdala as well as the fully-kindled behavioral convulsions.

\section{METHOD}

\section{Animals.}

The subjects were 59 male Wistar albino rats from Woodlyn Farms, Guelph, Ontario. They were maintained individually in stainless steel cages $(24.5 \times 17.5 \times 18.5 \mathrm{~cm})$ with water and Purina rat chow available ad libitum. Light dark cycles were kept at approximately 14 and $10 \mathrm{~h}$ (hours). The animals weighed $250-300 \mathrm{~g}$ at the time of surgery.

\section{Surgical Procedures.}

All subjects were anesthetized with pentobarbital $(50 \mathrm{mg} / \mathrm{kg})$ and received a single injection of atropine $(0.16 \mathrm{mg} / \mathrm{kg})$ prior to surgery. A modified Krieg stereotaxic instrument was used to maintain the animal's head in the deGroot plane (1963) for commissure transection and/or electrode implantation.

The device used for making the transections was a No. 22 scapel blade which had the back or noncutting edge ground down to within 1 $\mathrm{mm}$ of the cutting edge (Fig. 1). This blade was manipulated either by hand (with a No. 4 handle) or with a micromanipulator.

Transection of the rostral forebrain commissures such as the corpus callosum, anterior commissure, and hippocampal commissure was accomplished using an anterior approach. This approach consists of first exposing the skull, and then drilling a $2 \mathrm{~mm}$ wide groove over the midline, beginning at $5 \mathrm{~mm}$ and extending to $13 \mathrm{~mm}$ anterior to Bregma. The groove was drilled to a depth which left a fine sheet of bone

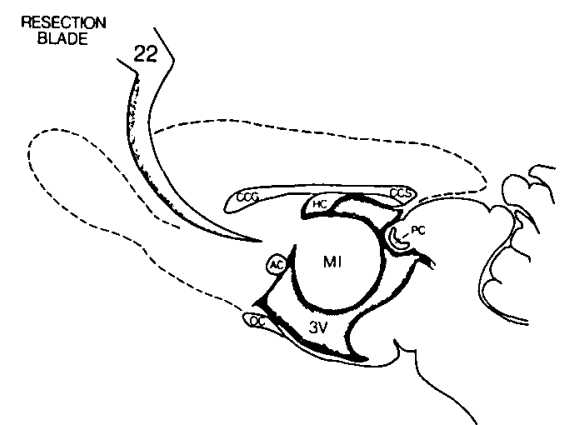

Figure 1-Schematic diagram of a midsagittal view of the forebrain commissures and the surgical approach to a subcallosal section.

above the dura. The midline suture was no longer supportive and the knife blade was slipped easily between the bone flaps with no resistance. After the tip of the blade penetrated the dura, it was inserted between the olfactory bulbs and beneath the superior sagittal sinus. The blade was then passed caudalward to the distance required, lowered and withdrawn. For example, to section the corpus callosum the blade was passed posteriorly $10 \mathrm{~mm}$ from the posterior end of the drilled groove. It was then lowered $4 \mathrm{~mm}$ and withdrawn $5 \mathrm{~mm}$ before being lowered an additional $2 \mathrm{~mm}$ to transect the genu. When a subcallosal section was made, however, the angle of insertion was $45^{\circ}$ and the knife tip was passed beneath the genu of the corpus to make the section (Fig. 1).

The caudal forebrain commissures were generally sectioned from a posterior approach. To achieve entrance, an $8 \mathrm{~mm}$ long slot was drilled over the midline, extending $2 \frac{1}{2} \mathrm{~mm}$ anterior and $5 \frac{1 / 2}{2}$ posterior to Lambda. The knife tip was inserted again between the cerebral hemispheres and above the colliculi. This approach was used to reach the posterior corpus callosum, posterior commissure, habenular commissure and the massa intermedia. The only problem with the posterior approach was the necessity of penetrating the superior sagittal sinus. Incision of the latter, of course, produced substantial bleeding; however, with pressure from a cotton ball, the bleeding was terminated within 15 sec. No rat in the author's laborat- ory was ever lost using this approach.

Animals receiving commissurotomy or the transection-control procedure had their wounds closed with clips and were allowed 3 weeks rest before electrode implantation. The commissure-intact animals were merely anesthetized and 3 weeks later re-anesthetized for electrode implanation.

After the 3 week rest period, all subjects were implanted with two bipolar electrodes, using the stereotaxic coordinates $4.5 \mathrm{~mm}$ lateral to the midline, $0.2 \mathrm{~mm}$ posterior to Bregma, and $8.0 \mathrm{~mm}$ below the ventral aspect of the skull. Also, a ground wire was inserted into the skull between the frontal pole and the olfactory bulbs. All wires were then secured with dental acrylic. The electrode pins were positioned into a plastic cap (Molino and McIntyre, 1972) which was cemented to the acrylic assembly.

The electrodes were constructed of 2 twisted strands of $0.127 \mathrm{~mm}$ diameter diamel-insulated nichrome wire and reinforced with epoxylite. The electrodes were cut to length, with their exposed tips separated by the thickness of the diamel insulation.

\section{Histology.}

Following testing, animals were sacrificed with chloroform anesthesia and perfused with saline and formalin. The brains were removed 24 hours later and fixed in formalin for at least 3 additional days. Frozen coronal sections of $40 \mu$ were taken through the area of electrode tracts and commissurotomy. Mounted sections were stained with cresyl violet. Data were discarded from all animals not having electrode tips in both amygdalae, or animals having commissural sections out of the midline.

\section{Stimulations.}

Once per day, all animals received 5 seconds of $60 \mathrm{~Hz}$ sine wave stimulation at an intensity of $50 \mu \mathrm{A}$ peakto-peak. During stimulation the animals were free moving in a $48 \times 48$ $\mathrm{cm}$ observation box. The response to the stimulation was noted. When convulsions were produced, times 
were recorded from the beginning of the stimulation to the onset of bilateral forelimb clonus (latency), and from this clonus onset to its termination (duration). These measures are very reliable in the Wistar rat.

\section{Procedure.}

All animals received the daily kindling stimulus to one amygdala (primary site) until 6 clonic convulsions were evoked. Beginning 24 hours later, the contralateral amygdala (secondary site) was kindled daily until 6 convulsions were again triggered. The next day, the primary site was retested, and was stimulated once daily until convulsions were triggered.

\section{After-discharge.}

EEG records were taken from both bipolar electrodes in all animals. During stimulation, a mechanical relay was used to disconnect the leads from the polygraph and disconnect the ground lead from the animal. The polygraph was a 4 channel Grass model 7 instrument.

\section{Groups}

Eight groups were readily apparent from the histological assessment of commissure transection.

1. Intact $(\mathrm{N}=12)$ - electrode implantation only.

2. Sectioned Controls $(N=9)-$ the sectioning blade was passed between the neocortices with no corpus callosum (CC) damage.

3. Total Forebrain $(\mathrm{N}=7)$ - resection of the $\mathrm{CC}$, anterior and posterior commissures, massa intermedia, habenular and hippocampal commissures.

4. Total Corpus Callosum $(N=9)-$ resection of the $\mathrm{CC}$ and generally the dorsal hippocampal commissure.

5. Anterior Corpus Callosum ( $\mathrm{N}=$ 7) - resection of approximately the anterior one-half of the $\mathrm{CC}$, with occasional transection of the

Figure 2-Sections A, B, C and D are photo-macrographs of $40 \mu$ cresyl violet stained sections showing commissurotomy of the corpus callosum, all forebrain midline structures, massa intermedia, and anterior commissure respectively, in four different rats. Section $D$ also characterizes the damage occurring to approximately half of the rats experiencing complete transection of the septum.

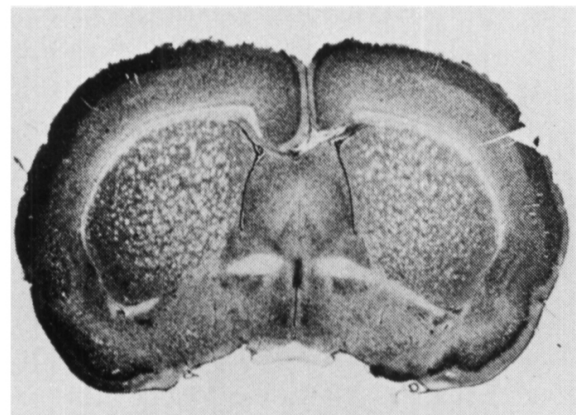

A

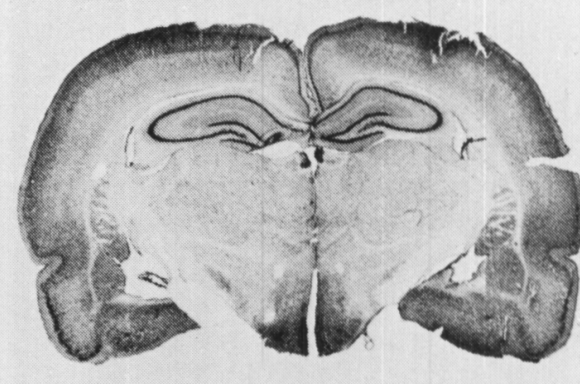

B
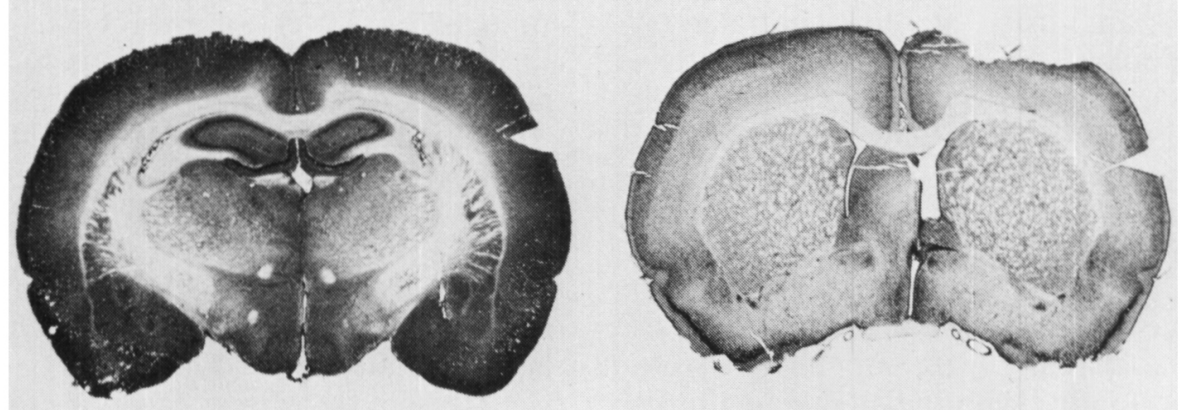

anterior hippocampal commissure.

6. Posterior Corpus Callosum ( $\mathrm{N}=$ 7) - resection of the posterior one-half to two-thirds of the CC as well as the dorsal or posterior hippocampal commissure and occasionally the dorsal aspect of the massa intermedia and the posterior commissure.

7. Subcallosal $(N=4)-$ resection of the massa intermedia and anterior commissure (AC).

8. Anterior $\mathrm{CC}+\mathrm{AC}(\mathrm{N}=4)-\mathrm{re}$ section of the anterior one-half of the $\mathrm{CC}$ as well as the AC.

\section{Statistical comparisons.}

All data comparisons were parametric (analysis of variance or $t$-tests). The $P$ values are two-tailed.

Where appropriate, analyses were based on difference scores between the two hemispheres for each animal. This was done to control for differences in "seizure susceptibility" between animals. The hemisphere which received primary site kindling was always selected randomly to ensure that the observed differences between the hemispheres were not biased by innate differences between the hemispheres.

The data of interest were the number of stimulations and ADs to first convulsion at each site; the latency to onset, duration and laterality of the convulsions; and the duration and laterality of the AD.

\section{RESULTS}

Based on histological analysis, the previously mentioned 8 groups were assembled. Photomacrographs from 4 different representative animals are presented in Fig. 2.

Section A demonstrates a sectioned corpus callosum using the anterior approach. The damage to midline cortex and septum was minimal. Section B indicates a total forebrain commissurotomy using the posterior approach. Section $C$ demonstrates a subcallosal resection of the massa intermedia using a posterior approach. Section D presents a subcallosal resection of the anterior commissure using the anterior approach. Note the unilateral lesion of the right half of the septum, an effect which 


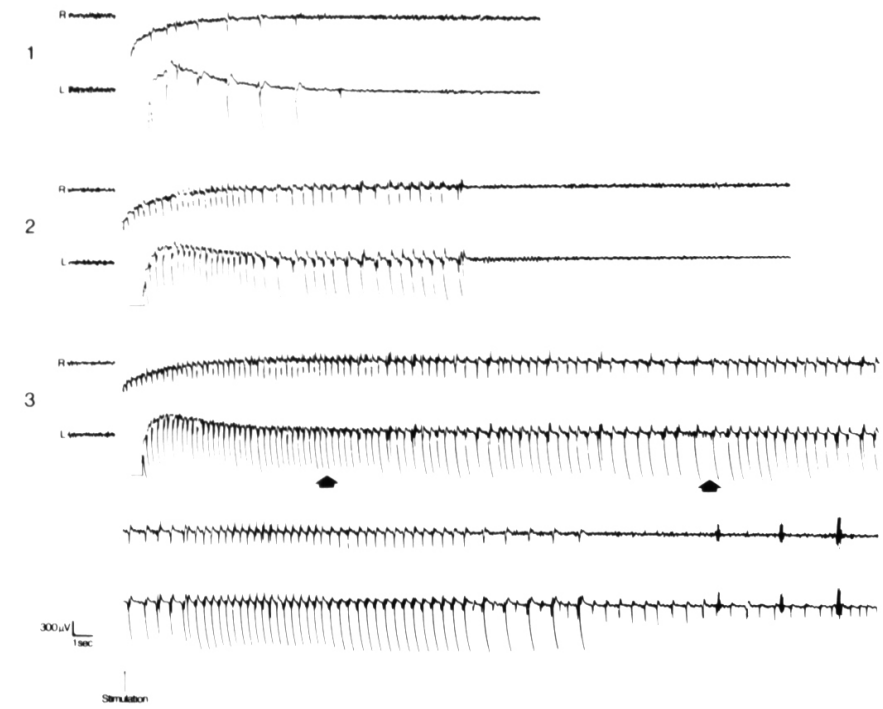

Figure 3-AD recorded from bipolar electrodes in the right (R) and left (L) amygdala following $5 \mathrm{sec}$. stimulation of the primary site in an intact rat. Records are present from (1) the first trial , (2) the trial midway between trial one and the first motor convulsion, and (3) the first motor convulsion trial. The arrows indicate the onset and offset of the clonus.
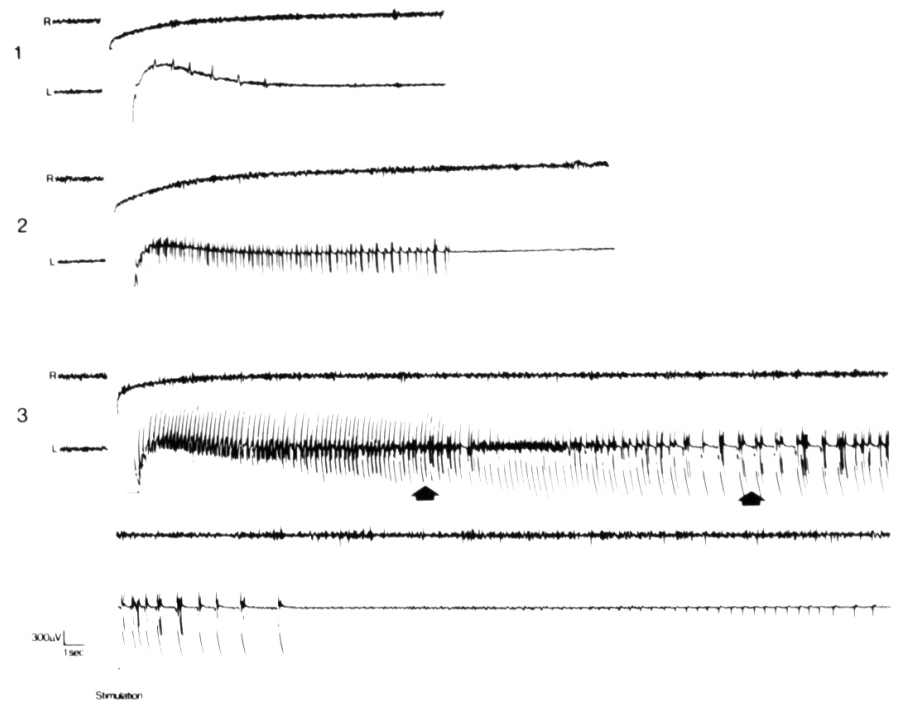

Figure 4-AD recorded from bipolar electrodes in the right (R) and left (L) amygdala following $5 \mathrm{sec}$. stimulation of the primary site in a total forebrain sectioned rat. Records are presented from (1) the first trial, (2) the trial midway between trial one and the first motor convulsions, and (3) the first motor convulsion trial. The arrows indicate the onset and offset of the clonus. frequently follows transection of this structure.

In an agreement with previous reports, repeated stimulation of the amygdala in intact animals led to the appearance of epileptiform AD which evolved to progressively longer durations and greater amplitudes, and eventually spread to involve both amygdalae (see Fig. 3). This was true for all groups except the Total Forebrain group and Anterior $\mathrm{CC}+\mathrm{AC}$ group. All animals in the latter 2 groups, with 2 exceptions, had $A D$ recorded only at the stimulated structure (see Fig. 4).

The behavioral response of the intact animals to the stimulation progressed from a brief arrest of activity on trial one through a sequence involving eye blinking, chewing, head bobbing and, eventually, bilateral synchronous clonus of the forelimbs, and episthotonus with the animal supported on hindlimbs and tail. This sequence was also observed in the 3 groups: Posterior CC, Subcallosal, and Sectioned Control. The other sectioned groups exhibited lateralized motor convulsions confined to the forelimbs and face contralateral to the stimulated amygdala. It is of interest to note that during kindling, as previously mentioned, one of the early automatisms observed is ipsilateral eye closure. All animals exhibited this response, even the Total Forebrain group, indicating the response's subserviance to an uncrossed motor system; the facial convulsion, on the other hand, like the clonus, was confined to the contralateral musculature, indicating a crossed motor system involvement in the final convulsion form.

The convulsion form of the Total Forebrain group exhibited the most dramatic lateralization. With these animals, the limbs ipsilateral to the stimulated amygdala were used for support while the clonus proceeded in the contralateral forelimb, face, ear and, frequently, the contralateral hindlimb. As a result of the latter, opisthotonus was seldom observed. For the Total CC, Anterior CC and Anterior $\mathrm{CC}+\mathrm{AC}$ animals, the lateralization was generally manifested as a contralateral forelimb clonus with ipsilateral forelimb raised in a flexed position in front of the animal. These convulsions were performed with the animal in a position of opisthotonus. With several animals in the Total CC and Anterior
CC groups, the convulsion would, after 4 or 5 evocations, become bilateral and generally asynchronous.

When examining the rate of kindling for the various groups, neither the number of stimulations nor the number of ADs to first convulsion was different (see Table 1). The data clearly indicate that the lack of interhemispheric communication does not retard the kindling process. This lack of an effect is further emphasized by the statistical similarity between groups, in the convulsion onset (latency) and duration data, as well as duration of the primary site AD.

As had been previously reported, when using a fairly low intensity stimulus the AD is not always present on the first stimulation. It is for this reason that the number of stimulations and number of $\mathrm{ADs}$ to first convulsion are generally not the same, as may be seen in Table 1. Also, it may be seen that when kindling the primary site, the number of trials with $\mathrm{AD}$ is different between the two hemispheres. These data reflect the fact that a few trials of unilateral $A D$ are generally produced before AD propagates to the con- 
TABLE I

Number of stimulations and ADs to first convulsion at the primary and secondary sites. The \% change scores (trials or latencies) were calculated by $P-S / P \times 100$ where $P$ is the score at the primary site and $S$ is the score at the secondary site. $\bar{X}$ : mean. $R$ : range. N: number of animals per group.

\begin{tabular}{|c|c|c|c|c|c|c|c|c|c|c|c|}
\hline \multirow[b]{3}{*}{ GROUP } & \multirow[b]{3}{*}{$\mathrm{N}$} & \multicolumn{4}{|c|}{ RESULTS AT PRIMARY SITE } & \multicolumn{6}{|c|}{ RESULTS AT SECONDARY SITE } \\
\hline & & \multicolumn{4}{|c|}{$\begin{array}{ll}\text { No. stim. to first } & \text { MEAN } \\
\text { convulsion } & \text { No. AD to first } \\
\text { convulsion }\end{array}$} & \multicolumn{2}{|c|}{$\begin{array}{l}\text { No. stim. to first } \\
\text { convulsion }\end{array}$} & \multicolumn{2}{|c|}{$\begin{array}{l}\text { No. AD to first } \\
\text { convulsion }\end{array}$} & \multirow[b]{2}{*}{$\%$ transfer } & \multirow{2}{*}{$\begin{array}{l}\text { \% latency } \\
\text { shift }\end{array}$} \\
\hline & & $\bar{x}$ & $\mathrm{R}$ & $P$ & $S$ & $\bar{x}$ & $\mathbf{R}$ & $\mathrm{P}$ & $S$ & & \\
\hline Intact & 12 & 14.6 & $(7-23)$ & 14.6 & 13.5 & 10.5 & $(6-16)$ & 6.7 & 9.0 & +21.6 & -109.9 \\
\hline Sectioned Control & 9 & 13.7 & $(5-24)$ & 13.6 & 11.5 & 9.1 & $(4-14)$ & 7.8 & 8.0 & +18.3 & -20.1 \\
\hline Total Forebrain & 7 & 11.3 & $(7-14)$ & 11.1 & 3.9 & 5.7 & $(4-9)$ & 2.3 & 5.7 & +41.5 & -73.5 \\
\hline Total CC & 9 & 14.2 & $(6-25)$ & 14.2 & 10.8 & 10.2 & $(4-24)$ & 8.1 & 9.8 & +28.2 & -37.4 \\
\hline Anterior CC & 7 & 14.3 & $(5-30)$ & 13.1 & 10.7 & 6.9 & $(3-10)$ & 5.3 & 6.6 & +38.4 & -85.3 \\
\hline Posterior CC & 7 & 18.4 & $(12-29)$ & 16.6 & 13.7 & 10.9 & $(8-18)$ & 7.3 & 9.1 & +38.1 & -72.0 \\
\hline Subcallosal & 4 & 18.3 & $(9-25)$ & 17.8 & 13.0 & 6.8 & $(2-12)$ & 4.3 & 6.3 & +48.8 & -94.7 \\
\hline Anterior $\mathrm{CC}+\mathrm{AC}$ & 4 & 13.5 & $(9-19)$ & 12.5 & 0.0 & 9.0 & $(6-10)$ & 0.5 & 8.8 & +29.6 & -60.5 \\
\hline
\end{tabular}

tralateral amygdala in intact animals. In addition, the commissurotomy data in Table 1 indicate the importance of the joint action of anterior commissure and the anterior corpus callosum in realizing the homotopic AD response with a kindled amygdala site. Both the Total Forebrain group and the Anterior $\mathrm{CC}+\mathrm{AC}$ group were very slow in their development of homotopic AD. In fact, the latter group had no animal with bilateral AD during primary site kindling, and the former group had onty 2 of 7 animals exhibiting bilateral AD. The Subcallosal animals had their anterior commissure sectioned but still bilateral AD was evoked, and the Anterior $\mathrm{CC}$ and Total CC animals both had bilateral AD. Therefore, singly, sectioning the anterior commissure or the anterior corpus callosum did not significantly reduce the bilateral AD propagation following amygdala kindling, but sectioned jointly the propagation was markedly obstructed.

During kindling of the secondary site, the same behavioral sequence of events was observed. However, the number of trials to first convulsion as well as the number of ADs to first convulsion were significantly less than that achieved at the primary site $\left(p_{1}<.0001\right)$. There were no significant differences between the groups in terms of the rate of transfer from the primary site to the secondary site (see Table 1). The sur- prising result was that total forebrain commissurotomy had no effect on the transfer. These data strongly indicate the importance of brainstem mechanisms for achieving the transfer effect.

Twenty-four hours after triggering the 6th convulsion from the secondary site, re-testing of the primary site began. As it has been previously shown (McIntyre \& Goddard, 1973), there was a marked interference effect in evoking behavioral convulsions from intact animals following secondary site kindling. It required between 4 and 5 daily trials before a convulsion was again triggered from the primary site. However, it is clear that the interference effect is substantially dependent upon the integ- rity of anterior portion of the corpus callosum. One can see from Table 2, in all animals having the anterior $\mathrm{CC}$ sectioned (alone or with other commissures), a convulsion was triggered from the primary site on the first re-test trial. On the other hand, the Posterior $\mathrm{CC}$ animals and the Subcallosal animals were indistinguishable from the intact and Section Control group. Also, there were 2 animals which only had the genu of the corpus callosum sectioned; they behaved like intact and sectioned control animals, suggesting that within the anterior portion of the corpus callosum, the region interconnecting motor cortex areas 4, 6 and posterior 10 is the most important for this effect.

TABLE II

Number of stimulations and ADs to first convulsion at the primary site retest.

\begin{tabular}{lccccc}
\hline & RESULTS AT PRIMARY SITE RETEST & \multicolumn{2}{c}{$\begin{array}{c}\text { MEAN } \\
\text { An to first }\end{array}$} \\
GROUP & $\mathrm{N}$ & $\bar{X}^{\text {No. of stim. to first }}$ & \multicolumn{2}{c}{$\begin{array}{c}\text { No. AD tonvulsion } \\
\text { convulsion }\end{array}$} \\
Intact & 12 & 4.8 & $(3.8)$ & 4.8 & 4.7 \\
Sectioned Control & 9 & 4.3 & $(2-6)$ & 4.3 & 4.3 \\
Total Forebrain & 7 & 1.0 & - & 1.0 & 0.6 \\
Total CC & 9 & 1.0 & - & 1.0 & 1.0 \\
Anterior CC & 7 & 1.0 & - & 1.0 & 1.0 \\
Posterior CC & 7 & 3.4 & $(2-5)$ & 3.4 & 3.3 \\
Subcallosal & 4 & 3.5 & $(2-5)$ & 3.3 & 3.3 \\
Anterior CC $+\mathrm{AC}$ & 4 & 1.0 & - & 1.0 & 0.5 \\
\hline
\end{tabular}

$\overline{\mathrm{X}}$ : mean. R: range. N: number of animals per group. P: primary site electrode. S: secondary site electrode. 


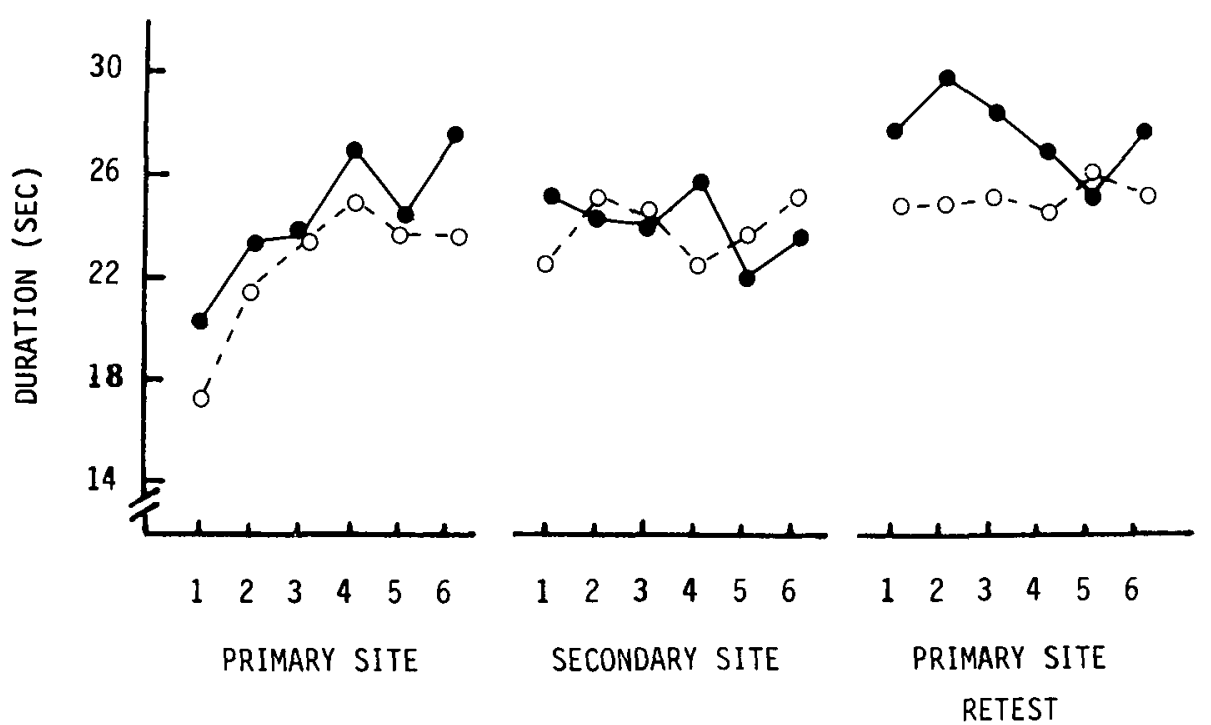

Figure 5-Group mean durations of convulsion - time from beginning to end of forelimb clonus. Filled circle: Total Forebrain sectioned animals. Open circles: all other groups excluding the Anterior $\mathrm{CC}+\mathrm{AC}$ group.

The latencies for each convulsion are presented in Fig. 4. Within each series of 6 convulsions, the latencies decreased $(p<.00001)$. In addition, as has been previously shown (McIntyre and Goddard, 1973), there was a significant increase in latencies between the primary series and the secondary series $(p<.00005)$. This latency shift was seen in all groups with no significant differences evident between the groups. Following the 6 convulsions at the secondary site, the primary site retest latencies were significantly shorter than the secondary site latencies $(\mathrm{p}<.0009)$, but longer than the original primary site latencies $(p$ $<.01)$. The only exceptions were the Total Forebrain group and the Anterior $\mathrm{CC}+\mathrm{AC}$ group. In the former group their latencies at the primary site re-test were slightly lower than their original series $(p<.05)$, whereas, in the latter group, their primary site re-test latencies were the same as their original series. It is puzzling that the animals in those 2 groups showed a latency shift between primary and secondary site, but no effect between secondary and primary site re-test.

The durations of each behavioral convulsion are presented in Fig. 5. It can be seen that during the primary series, the durations progressively increased $(p<.0009)$, but soon after became relatively constant for the well as the secondary series. There was, however, a slight increase in duration when the primary site was re-tested $(p<.007)$. These effects were consistent between all groups with no reliable differences among remainder of the primary series as

groups. The data suggest that the secondary site kindling provides access to a previously developed motor convulsion mechanism and thus, the progressive increase in durations are not seen at that secondary focus (or at the primary site retest).

The duration of $A D$ progressed during the course of primary site kindling $(\mathrm{p}<.00001)$, but by the time convulsions were evoked, it had stabilized between 50 and $80 \mathrm{sec}$. for all groups. The homotopic AD duration at the contralateral (secondary) site during the 6 convulsions was statistically the same as that at the primary (stimulated) site, except for the Total Forebrain group and the Anterior $\mathrm{CC}+\mathrm{AC}$ group. In the former group only 2 animals had $A D$ at the secondary site of the same duration as the primary site $(p<.03)$. However, there were no differences between groups at that secondary site, and the contralateral site had an AD duration similar to the stimulated (secondary) site, except, again, for the Total Forebrain and Anterior $\mathrm{CC}+\mathrm{AC}$ groups.

When returning to the primary site

Figure 6-Group mean latencies from stimulation to onset of clonus for each of the 6 trials at the two sites. Filled circle: Total Forebrain sectioned animals. Open circles: all other groups, excluding the Anterior $\mathrm{CC}+\mathrm{AC}$ group.

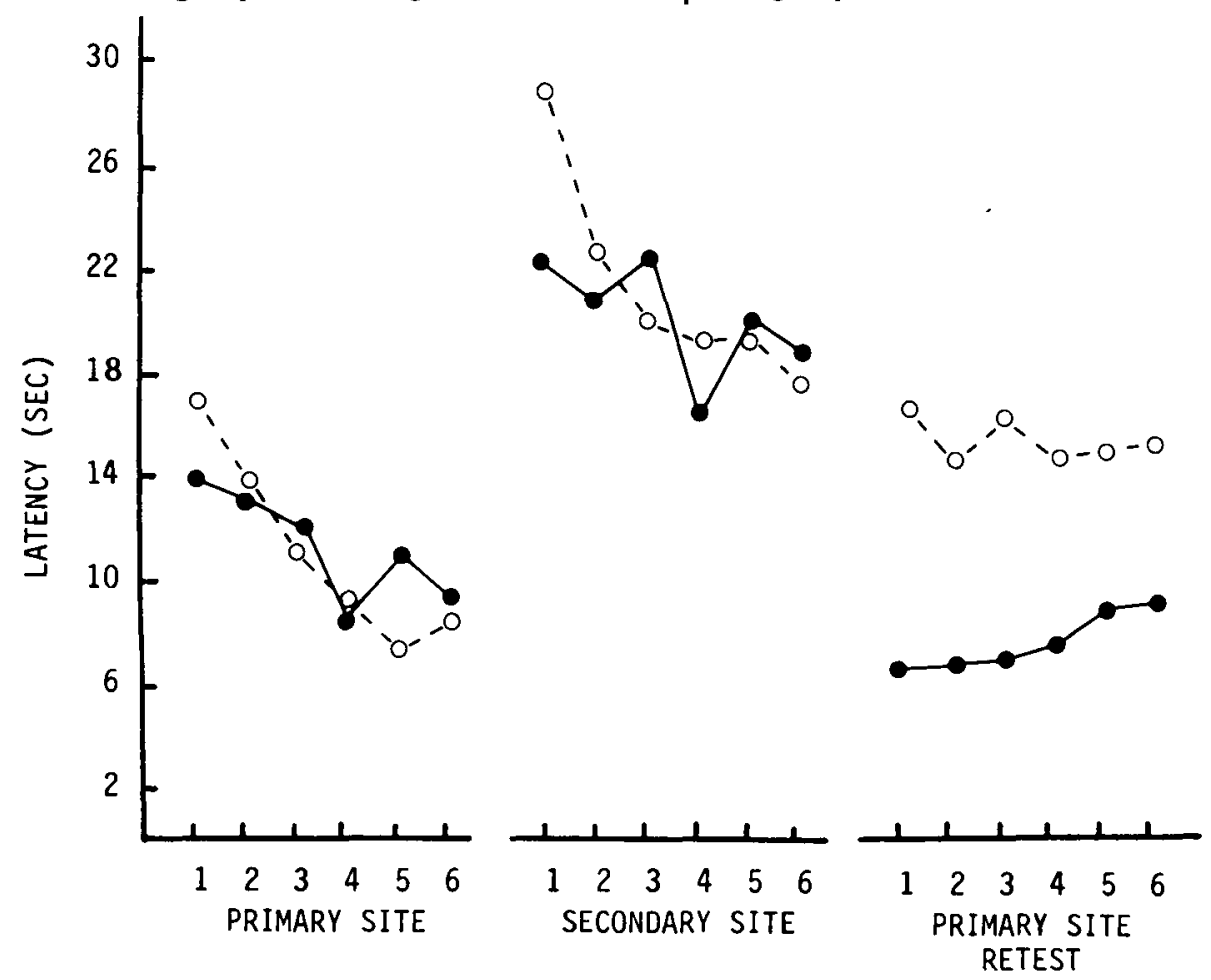


for re-testing, there again was a progressive increase in AD duration until convulsions were again evoked in the intact, Sectioned Control, Posterior $\mathrm{CC}$ and Subcallosal groups. Once convulsions were provoked, the AD duration for all groups stabilized at a value similar to that seen during the original primary site convulsion series. The results at the contralateral site during primary site re-test were identical to those previously described for the original primary site convulsion series. It seems that after convulsions are established, the AD duration during convulsion trials is quite stable.

\section{DISCUSSION}

The present observations confirm previous reports of behavioral convulsions being kindled by amygdala stimulation. The data show that the laterality of the motor convulsion is initially dependent upon the rostral corpus callosum (excluding the genu). That is, animals with the anterior half of the $\mathrm{CC}$ sectioned experienced a unilateral convulsion of the forelimb, ear and face contralateral to the stimulated amygdala. In most cases, with small transections and repeated convulsions (6-10 in most cases), the form of the convulsion eventually became bilateral. However with total forebrain commissurotomy, the convulsions remained unilateral. There was also a dissociation of the AD laterally and the motor convulsion. In animals with anterior $\mathrm{CC}$ sections, the convulsions were unilateral (initially), but the AD was bilateral. This was also true for the Total CC group, whereas the total forebrain sectioned animals maintained unilateral AD.

The rate of kindling among the groups was not different. It seems, therefore, that interhemispheric associations are neither necessary to kindle convulsions nor significantly influential in their etiology. In fact there was a tendency, albeit nonsignificant, for the total forebrain sectioned animals to develop convulsions faster than the controls perhaps because of the reduced interhemispheric inhibition occasionally reported (Mutani et al., 1972).
Racine et al (1972) had previously described a deficit in kindling following midline transection in rats. However, a recent replication attempted by Racine (personal communication) failed to confirm the deficit effect and indicated midline transection was without significant effect on the rate of kindling. On the other hand, Wada and Sato (1973) have reported a facilitation in kindling rate following midline forebrain commissurotomy in cats. Thus, it seems that midline transection is either without effect on kindling rates or perhaps is even facilitory.

When kindling the secondary site, as previously reported (e.g., McIntyre \& Goddard, 1973), positive transfer occurred. Importantly, no commisurotomy, not even total forebrain sectioning, interfered with this effect. These data strongly indicate the importance of brainstem mechanisms in producing the transfer effect between hemispheres. It is certainly conceivable that transfer could occur with extensive commissurotomy if $\mathrm{AD}$ was present at the contralateral site, but when no such AD was evoked (e.g., Total Forebrain Group) and transfer occurred, it clearly indicated bilateral AD at the level of the amygdala is not important for the transfer effect. Likely the AD was bilateral posterior to the commissurotomy, at the level of the brainstem, and that this is the salient dimension for transfer. This view is consistent with the data of Wada and Sato (1974) which show "that the activation of the midbrain and the possible other brainstem structures is of prime importance for the involvement of the contralateral hemisphere and thus the development of bilateral convulsive seizure ....'

Further support for a midbrain or brainstem convulsion mechanism is gleaned from the convulsive duration data. The convulsions progressively increased in duration over the first few primary site evocations, but soon after became stabilized, as reported by others (e.g., Pinel et al., 1973). This progressive increase was not seen at the secondary site. In addition, the durations at the secondary site were the same as the primary site. Importantly, commis- surotomy had no influence on the durations; that is, the convulsions were of the same duration independent of the side from which they were provoked, or which limbs were involved. These data suggest that the secondary site makes use of, or gains access to, a motor mechanism developed during primary site kindling, and that this mechanism, as previously proposed, is likely posterior to the transection and native to the midbrain or brainstem.

There was a marked increase in latency to convulsion at the secondary site compared to the primary site. Interestingly, the transected animals also exhibited this shift and were not reliably different from the intact animals.

After returning to the primary site for re-test, all groups, except the Total Forebrain group and the Anterior $\mathrm{CC}+\mathrm{AC}$ group, showed latencies that were higher than the original primary site latencies. Together these data suggest that commissurotomy slightly reduces the interference effects as manifested in latency to onset of a convulsion, but only if the transection is extensive. On the other hand, merely the anterior portion of the corpus callosum need be sectioned to obviate the interference effect as manifested by convulsion blockage during primary site re-test. It seems that motor aspects of the inhibition are mediated via motor cortex and its callosal projections, yet the interference effect still exercises its influence by delaying the convulsion onset, unless the transection is extensive, including at least the anterior $\mathrm{CC}$ and the anterior commissure. The interference effect, therefore, is most labile at the convulsion evocation level and less so in terms of onset latency.

The AD duration data also reflected the interference effect. It was observed that the AD duration progressively increased during kindling of the primary site as well as the secondary site, but once convulsions were evoked, the AD had stabilized. When returning to the primary site for re-test, however, the AD again progressively increased in duration until convulsions were evoked. This progressive increase only occurred if 
the convulsions were initially blocked, and required rekindling. That is, if the convulsion was provoked on the first re-test trial, there was no change in AD duration across the 6 re-test trials, or comparing the latter to the final $A D$ durations during the original primary site series. Therefore, when the interference effect appeared as convulsion blockage, it was displayed in the amygdala $A D$ duration.

Finally, the AD data clearly showed that joint transection of the anterior $\mathrm{CC}$ and the anterior commissure was necessary to retard AD propagation between amygdalae. Neither of the structures, when sectioned singly, prevented the homotopic $\mathrm{AD}$ response. When the convulsion was repeated several times, some of the animals with the less extensive transections developed contralateral amygdala $\mathrm{AD}$. These data are similar to those of Problete et al., (1959) and Frost et al., (1958) which demonstrated that, in the monkey, AD from the temporal pole or the amygdala can be prevented from reaching the homotopic area if the anterior commissure is sectioned. However, in the absence of the preferred path, secondary avenues will propagate the discharge between the hemispheres, particularly if the discharge becomes generalized.

\section{DISCUSSION}

Dr. Wada: I would like to ask Mr. McCaughran to comment briefly on our observations on the forebrain bisected rats in relation to Dr. McIntyre's elegant study. Mr. McCaughran: We have been using the split brain rat preparation during the past 2.5 years and looked at the effects of splitting the various portions of the corpus callosum or commissures on seizure development. We find that our results are almost identical to your findings. We disagree on a couple of points. Firstly, we find that sectioning of the anterior callosum alone is sufficient to attenuate the propagation or afterdischarge to the contralateral amygdala. I believe that you said that in your animals it had to be in conjunction with the anterior commissure section. We also found that there was propagation into the contralateral MRF and also the contralateral motor cortex in these animals. I find your results with the motor cortex a little bit difficult to understand. Dr. Mclintyre: Keep in mind that you've got electrodes spread around bilaterally. I've got the bilateral amygdala only but as $I$ indicated in the manuscript, I feel very firmly that there is bilateral afterdis- charge at a downstream level which is exactly what you have just described. $M r . M c C a u g-$ hran: We had four groups of animals. One group was completely bisected at the corpus callosum, portions of the hippocampal commissure and the anterior commissure. We had a second group that was the corpus callosum only, a third group that was in fact a control group. We find in terms of seizure duration that the animals which are completely bisected tend to have much longer seizures and this is followed in turn by the animals with only a corpus callosum transection and these are then followed by the anterior commissure and then finally the control animals tend to have the shortest duration. Dr. Burnham: Perhaps the question might be posed as to why there is an appreciable latency when some triggering sites are used. Couldn't your interference data indicate that every $A D$ excites both excitatory and inhibitory processes in the brain and that the course of the propagation of that $\mathrm{AD}$ - and therefore the latency of the motor seizure - depends on the balance of those processes. I know in my experiments the amygdala animals always tended to have the shortest motor seizure latencies, and I also found the amygdala to be very good at resisting interference. Dr. Racine: Do you have any ideas about what brainstem structure might be involved in these effects? $D r$. McIntyre: I really don't know and I have no data to reflect on. The only data that are available are the reticular lesion stuff in terms of that part and these aren't so interesting. It was mentioned earlier in the context of the cerebellum. I have one animal in which l've made cerebellar lesions and there is no interference effect, yet the transfer is perfectly okay. $D r$. Burnham: Beautiful transfer data. I wish I'd known about it before I wrote up my discussion. The Racine-Burnham theory of reactive propagation (limbic-limbic) as basic to transfer certainly looks a bit shaky unless there are different mechanisms for ipsilateral and contralateral transfer. McIntyre later said that there might be, but am I right that you found contralateral transfer in split-brains that still had unilateral convulsions and no contralateral reactive propagation? Dr. McIntyre: Yes, you were describing going to the secondary site and having the seizure starting off at what you referred to as maximal level. It starts off as nice little monophasic stuff and then becomes more complicated and evolves in the same fashion as the primary site except that it does it an awful lot faster, which would suggest to me that it is developing its own style within itself, but then once it propagates to this already developed mechanism downstairs, you see convulsions. $D r$. Wada: 1 was very pleased to hear your meticulous observation of clinical manifestation in the rat's kindling process. You do see ipsilateral eye movement before contralateral manifestation develops. This is exactly what we see in cats, baboons and rhesus monkeys, so there is very little difference among them as far as the early pattern of clinical seizure development goes. In our split brain cats, the number of stimulations required was not too different between the primary and secondary sites but the primary site kindling was so fast it is difficult to know whether there was any transfer or not. In Senegalese baboons, on the other hand, the final Stage 5 generalized convulsion of focal onset which develops from the secondary site has several characteristic features which differentiate it from that of the primary site with its abruptness of emergence and disappearance from the background of ongoing Stage 1 electroclinical seizure manifestation. The clinical and electrographic seizure pattern of the secondary site convulsion has produced an exact mirror image of that of the primary site in terms of focal and laterizing features and this finding is difficult to understand if the development of the secondary site final stage convulsion is due to tying into whatever neurocircuit which has been built up by the primary site stimulation. It is possible that the primary site kindling might have "sensitized" the contralateral neurocircuit which ties into the final primary generalized seizure mechanism integrated in the lower brain stem, at least in baboons. As I already mentioned, one of the striking features of the secondary site early convulsion is that it develops within about one week but one cannot maintain it. In two animals, we observed that it regressed to Stage 1 or Stage 2 and in spite of continued stimulation of over 100 days, there was no more seizure development. This is in contrast to about 70 days which is required for the primary site kindling. After 100 days of unsuccessful kindling, at the secondary site, the animals developed an established pattern of electroclinical convulsion upon first stimulation at the primary site although there was some minor modification of the electrographic seizure pattern. Dr. McIntyre: Perhaps the interference effect seems to work both ways. It works from the primary site onto the secondary site and from the secondary site back onto the primary site again. In terms of latency relationships you would have to say that the strongest interference effect really is from the primary site to the secondary site. Maybe what you are describing is that once you get convulsions from the secondary site they are really substantially inhibited by that primary site and you never develop any inhibition back the other way because that secondary site never gets going and as you go back, bingo. there is none. Dr. FernandezGuardiola: Working with a group of temporal lobe epileptic patients with implanted electrodes in both amygdalae, we had the opportunity to stimulate this structure with trains of electrical pulses ( $1 \mathrm{sec}$ train duration, $1 \mathrm{msec}$ pulse duration $50 \mathrm{~Hz}, 0.3 \mathrm{ma}$ ) and single pulses. The recording of the contralateral amaygdala displayed a fast response of about $12 \mathrm{msec}$ latency and a late response of 30 or more $\mathrm{msec}$ latency. We believe that there are two ways of interamygdalae connections: one rapid way. presumably through the anterior commissure, and the other through the brain stem reticular formation. This latter possibility is consistent with what has been demonstrated by Guzmán-Flores (1969) in the cat. I wonder if this peculiar amygdala interconnection circuit could explain your results in the split brain preparation and the interference effect? Dr. McIntyre: It would be very interesting to see if in fact that second pulse survived transection. Dr. Wada: Augusto's finding is consistent with what we found on interamygdala latency with respect to transmission of interictal discharge from the primary site to the secondary site or vice versa. It was about $30 \mathrm{msec}$ both ways and this is the same in intact cats as well as split brain cats. Dr. Burnham: I've been thinking off and on about 
Graham's question earlier of why do you have a latency in well kindled animals. Of course you don't in some well kindled animals and some of my amygdala experiments have no measurable latency at all. Then might the question be, why do you have a latency in some kindled animals and not in others in the onset of motor convulsions? I've noticed that my latencies are shortest from the amygdala generally which is also a structure which is good at resisting interference. Do you suppose that your interference effects could explain these latencies? In other words, do we assume that stimulating and getting afterdischarge probably produces excitation plus some kind of inhibition; that some structures are better at fighting against the inhibition because of general seizure in that area? Dr. Mclntyre: If you find you can evoke convulsions from that primary site you do have convulsion failures periodically from it, suggesting that it is not really totally immune to that. You have a great many more convulsion failures at the secondary site. Then, when you go back to the primary site you start seeing convulsion barriers again suggesting that it can react back onto the site which is generating it, that it is not totally immune to it, and perhaps that's why it takes these things a long time to occur. I would be interested in knowing whether this phenomenon exists at a cortical level where you turn the juice on and you have your convulsion instantly. Dr. Wada: In cats, Rhesus monkeys, and baboons we have not observed "instant convulsion". There is always a set of latencies with the AD "threshold" stimulation although the latency tends to be shorter as animals are kindled better. Could not this be primarily a function of stimulation intensity? Dr. Racine: Your data on interference are interesting but the transfer data are fantastic! Do you have any ideas on which brain stem structures might be involved in these effects? Dr. Mclntyre: I agree it must be in the brainstem but I do not know which structure.

\section{REFERENCES}

BURNHAM, W. M. (1971). Epileptogenic modification of the rat forebrain by direct and trans-synaptic stimulation. Doctoral Dissertation, McGill University.

DeGROOT, J. (1963). The Rat Forebrain in Stereotaxic Coordinates. North-Holland, Amsterdam.

FROST, L. L., BALDWIN, M. and WODD, C. D. (1958). Investigation of the primate amygdala: movements of the face and jaws. Neurology, 8, 543-546.

GODDARD, G. V., McINTYRE, D. C. and LEECH, C. K. (1969). A permanent change in brain function resulting from daily electrical stimulation. Experimental Neurology, 25, 295-330.

McINTYRE, D. C. and GODDARD, G. V. (1973). Transfer, interference and spontaneous recovery of convulsions kindled from the rat amygdala. Electroencephalography and Clinical Neurophysiology, 35, 533-543.

MUTANI, R., BERGANINI, L., FARIELLO, R. and QUATTROCOLO, G. (1972). An experimental investigation on the mechanisms of interaction of asymmetrical acute epileptic foci. Epilepsia, 13, 597-608.
PINEL, J. P., PHILlLIPS, A. H. and MacNEILL, B. (1973). Blockage of highlystable "kindled" seizures in rats by antecedent footshock. Epilepsia, 14, 29-37.

PROBLETE, R., RUBEN, R. and WALKER, A. E. (1959). Propagation of after-discharge between temporal lobes. Journal of Neurophysiology, 22, 538-553.

RACINE, R. J. (1972). Modification of seizure activity by electrical stimulation: 11 . Motor seizure. Electroencephalography and Cliniical Neurophysiology. 32, 281-294.

RACINE, R. J., OKUJAVA, V. and CHIPASHVILI, S. (1972). Modification of seizure activity by electrical stimulation: 111 Mechanisms. Electroencephalography and Clinical Neurophysiology, 32, 295-299.

TANAKA, A. (1972). Progressive changes of behavioral and electrographic responses to daily amygdaloid stimulation in rabbits. Fukuoka Acta Medica, 63, 152-164.

WADA, J. and SATO, M. (1973). Generalized convulsive seizure state induced by daily electrical stimulation of the amygdala in split-brain cats. Paper delivered to the American Electroencephalography Association, Boston.

WADA, J. A. and SATO, M. (1974). Generalized convulsive seizures induced by daily electrical stimulation of the amygdala in cats. Neurology, 24, 565-574.

WADA, J. A., SATO, M. and CORCORAN, M. E. (1974). Persistent seizure susceptibility and recurrent spontaneous seizures in kindled cats. Epilepsia, 15, 465-478. 